\title{
Accessing and Managing Open Medical Resources in Africa over the Internet
}

\author{
Rada Hussein ${ }^{\mathrm{a}}$, Aly Khalifa ${ }^{\mathrm{a}}$, Ana Jimenez-Castellanos ${ }^{\mathrm{b}}$, Guillermo de la Calle ${ }^{\mathrm{b}}$, \\ Maximo Ramirez-Robles ${ }^{\mathrm{b}}$, Jose Crespo ${ }^{\mathrm{b}}$, David Perez-Rey ${ }^{\mathrm{b}}$, Miguel Garcia- \\ Remesal $^{\mathrm{b}}$, Alberto Anguita ${ }^{\mathrm{b}}$, Raul Alonso-Calvo ${ }^{\mathrm{b}}$, Diana de la Iglesia ${ }^{\mathrm{b}}$, Jose M. \\ Barreiro $^{\mathrm{b}}$ and Victor Maojo ${ }^{\mathrm{b}}$
}

\author{
anformation Technology Institute, B148, Smart Village, KM 28 Cairo-Alexandria desert road, 12577, Giza, Egypt. \\ ${ }^{b}$ Biomedical Informatics Group, Facultad de Informática, Departamento de Inteligencia Artificial, Universidad \\ Politécnica de Madrid, Campus de Montegancedo, s/n, 28660, Boadilla del Monte, Spain.
}

\begin{abstract}
Recent commentaries have proposed the advantages of using open exchange of data and informatics resources for improving health-related policies and patient care in Africa. Yet, in many African regions, both private medical and public health information systems are still unaffordable. Open exchange over the social Web 2.0 could encourage more altruistic support of medical initiatives. We have carried out some experiments to demonstrate the feasibility of using this approach to disseminate open data and informatics resources in Africa. After the experiments we developed the AFRICA BUILD Portal, the first Social Network for African biomedical researchers. Through the AFRICA BUILD Portal users can access in a transparent way to several resources. Currently, over 600 researchers are using distributed and open resources through this platform committed to low connections.
\end{abstract}

\section{INTRODUCTION}

Recent reports have analyzed how new technologies could help improving health research and education in Africa. Several open tools are available and might be useful in this environment. However, the solution is not trivial, since tools are distributed, some advanced skills are needed to use them or do not support low connections.

In addition to open tools, the World Wide Web has contributed to an explosion of biomedical information resources, by stimulating publication, exchange and sharing of information and software resources. Its success has given rise to the medical "Web 2.0", with initiatives like a medical collaborative encyclopedia [1], various focused medical conferences such as Medicine 2.0 [2], special issues of scientific journals [3], focused medical informatics, and medically-related social groups [4].

In this Web-centered context, "cloud computing" has emerged, and is frequently seen as a great commercial success [5]. Cloud computing provides an interface to remote virtual resources accessible on demand [6], which can be controlled by the service owner. In pursuing their objectives, institutions and medical professionals that do not have enough storage and computing resources can manage their biomedical information through applications built on top of these types of services. By using cloud services for accessing information, authorized users from remote locations can have access to advanced computing infrastructures that they could not afford otherwise. While many companies, such as Google, IBM, Amazon, and Microsoft, were early adopters of cloud computing, its application to biomedicine has been only recently proposed [7-9], mainly for bioinformatics applications. Purely medical applications are increasing, although reports are still scarce from a research and academic perspective [9-11].

Extending this idea of adopting advanced computing technologies and expanding the range of medical applications in Africa, the authors have been involved in a series of initiatives, which, from a BMI perspective include: a) exchanging open biomedical data and resources, b) running complex applications and storing large amounts of medical data in remote computing infrastructures, and c) using Web 2.0 and e-learning approaches for training professionals and carrying out Internet-based biomedical collaborative projects. In such a distributed environment, which can support and extend previous initiatives for openly sharing information and extending both the "social" and the "semantic" capabilities of the Web, we report below on six experiments. They were conceived to demonstrate, as proof of concept, the feasibility of carrying out knowledge management (KM) and e-learning activities and remotely accessing advanced biomedical applications from two very different African locations: Cairo 
(Egypt) and Ngozi (Burundi). They address significant and distinct central issues in medical practice and research. Finally, experiments carried out have led to the development of the AFRICA BUILD Portal, intended to be the first meeting point for African biomedical researchers.

\section{THE GIB'S CLOUD PROTOTYPE FOR KNOWLEDGE MANAGEMENT}

In a first stage, we developed a prototype "cloud computing" facility at the Grupo de Informatica Biomedica, Universidad Politecnica de Madrid (GIB-UPM). Our prototype of cloud computing infrastructure [12] provided remote access to several BMI applications developed by the GIB. Access was provided as simple links to external online tools. Remote users only needed a standard Web browser to access the available services.

We designed this infrastructure to carry out six types of experiments from two different locations in Africa (Figure 1). In Egypt, we worked with staff and students from the Ministry of Communications \& Information Technology of Egypt. In Burundi, we worked with staff from the Ngozi Hospital. We selected these two locations for two main reasons: a) they radically differ in informatics resources, computing literacy level, budget, existing expertise in BMI, and other factors, suggesting two extremes of a broad range of environments to be found in Africa, and b) they also radically differ in biomedical objectives, since while the Egyptian group was mostly involved in supporting advanced biomedical research, in Burundi the informatics needs were focused on primary healthcare.

The Egyptian infrastructure included a network of advanced PCs and a state of the art local network with reasonably high bandwidth. In Burundi, two of the authors (AJC and GC) taught local users how to carry out the experiments. For the first experiments we used a "mid-range" laptop with a Intel Core Duo processor T2300, 100 GB Hard disk, 1GB DDR2 (RAM) running under Windows XP. For the internet connection, a maximum bandwidth of $306.8 \mathrm{~Kb} / \mathrm{s}$ through EDGE connection, quite close to the satellite connection, although there was great variability of the Internet connection depending on the time of the day.

With the above infrastructures, we carried out the six different experiments in Burundi and Egypt, using the GIB's cloud for addressing six different medical topics and subfields. In the experiments we wanted to address a wide range of KM applications for medical practice and research, evaluating them in these contrasting locations and environments: (i) searching a public inventory of biomedical informatics resources; (ii) exchanging medical information within a Web 2.0 collaborative environment; (iii) participating in e-learning courses developed in Europe; (iv) launching queries to an integrated medical database; (v) performing advanced medical image processing; and (vi) carrying out bioinformatics analyses on a remote supercomputer.

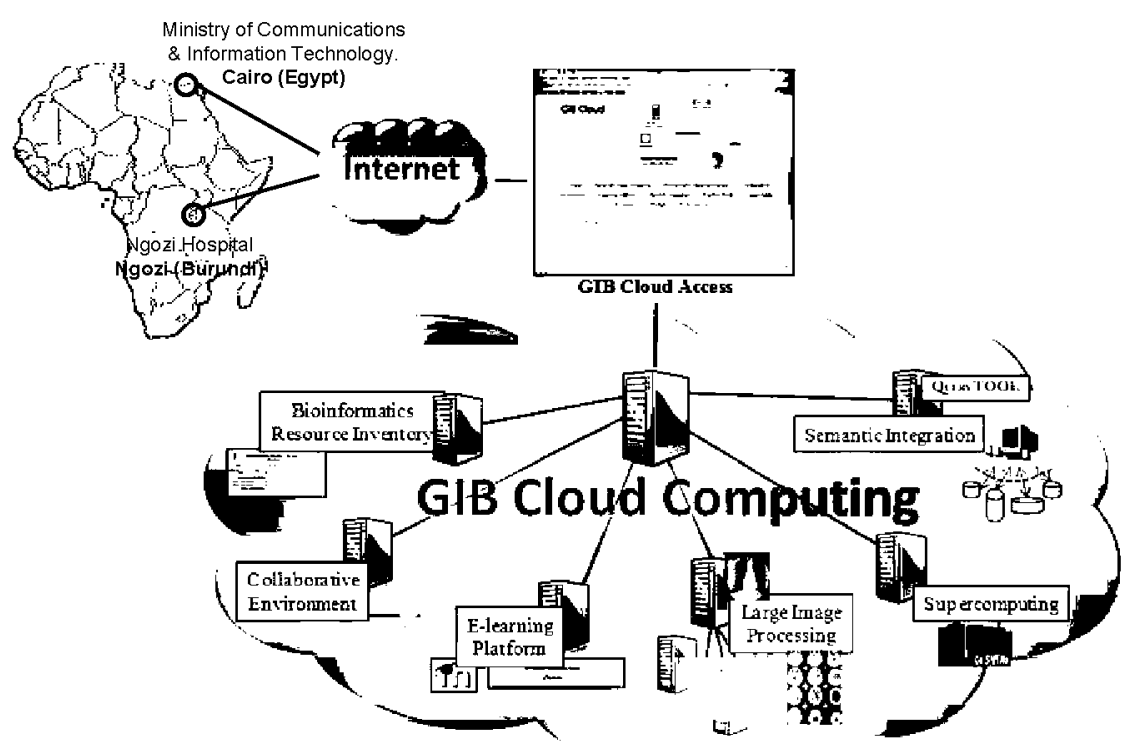

FIGURE 1. Experiments from Egypt and Burundi

Results of the experiments are found in Table 1. 
TABLE 1. a summary of the six experiments carried out in Egypt and Burundi

\begin{tabular}{|c|c|c|}
\hline Experiment & Egypt & Burundi \\
\hline 1. Accessing biomedical OSS & Rapidly accessed & Accessed, with minor delays \\
\hline $\begin{array}{l}\text { 2.Participation in a Web } 2.0 \text {-based } \\
\text { collaborative environment }\end{array}$ & $\begin{array}{l}\text { Users easily navigated, accessed the } \\
\text { system and shared files }\end{array}$ & Access was slower, but feasible (with minor delays) \\
\hline $\begin{array}{l}\text { 3.E-learning (Web and BMI } \\
\text { courses) }\end{array}$ & $\begin{array}{l}\text { Both courses successfully carried out } \\
\text { (see evaluation section) }\end{array}$ & $\begin{array}{l}\text { A complete, on-line, e-learning course was not } \\
\text { feasible. However, students were able to download } \\
\text { the courses' slides and explanations. }\end{array}$ \\
\hline $\begin{array}{l}\text { 4. Biomedical database } \\
\text { integration. }\end{array}$ & $\begin{array}{l}\text { Two different de-anonymized medical } \\
\text { databases were integrated and queried } \\
\text { through the GIB's cloud }\end{array}$ & $\begin{array}{c}\text { Users accessed and navigated the environment and } \\
\text { queried the databases provided by the Egyptian } \\
\text { users. }\end{array}$ \\
\hline $\begin{array}{l}\text { 5. Remote image processing, } \\
\text { analysis and storage. }\end{array}$ & Rapidly accessed and completed & Some delays, subject to improvement \\
\hline $\begin{array}{l}6 . \text { Access to external } \\
\text { supercomputer facilities }\end{array}$ & $\begin{array}{l}\text { Files with different sizes containing } \\
\text { biological data were rapidly processed. }\end{array}$ & $\begin{array}{c}\text { Only small files were processed, given the lack of } \\
\text { bioinformatics expertise }\end{array}$ \\
\hline
\end{tabular}

As conclusions of this experiment we found:

- Some of the users were not familiar with new information technologies, and the access to distributed tools placed as links in a Website was confusing for them. Making accessible all these tools from a common environment would facilitate its usage.

- Infrastructures and BMI applications must be linked to actual, real life health problems. In this context, addressing issues like AIDS, malaria, reproductive health and others must be considered having in mind the specific needs of local medical practitioners, policy-makers and patients.

- Various technical questions need to be addressed, such as interoperability, adherence to standards, security, reliability, bandwidth and reliable power (electricity), as the main limiting factors in some African regions.

\section{THE AFRICA BUILD PORTAL}

Within the framework of the AFRICA BUILD Project [12], we developed the AFRICA BUILD Portal (ABP) [13], applying what we had learnt in the GIB's Cloud prototype. The ABP is a Web 2.0 platform which supports the collaborative access to open resources oriented to health research and education. It has the external appearance and internal characteristics of a social network, intended to be used in Africa. Our objective was to improve the usability of this tool from Africa. It is also committed to low connections, to avoid the connectivity problems of many African institutions. Through the ABP users can access in a transparent way to several resources.

This tool was designed and implemented with African and European researchers in the development team, in order to ensure that the platform was linked to actual and real life health problems, enhancing South-South collaboration. The architecture of the ABP is modular (Figure 2) and integrates through several plugins different open research resources such as PubMed Central, BioMed Central, Moodle, Google News or the Mobility Brokerage Service. Every tool inside the ABP is enriched with social features such as "like", "tag", "share" or "follow". The main purpose is to stimulate user's collaborations to enhance South-South networks of biomedical researchers.

\section{CONCLUSIONS}

By using open source software, Web 2.0 applications and KM approaches, medical professionals from developing regions, with conventional computers and networking capabilities, can remotely access advanced computing infrastructures, process complex biomedical computations, and store medical data. For specific advanced KM applications, minimal infrastructure and basic training can be sufficient. In such a context, open healthcare information systems may be an effective and affordable solution for developing regions like many in Africa. Collaborative and volunteer efforts can also leverage related altruistic initiatives like those recently launched in Europe and the USA.

The AFRICA BUILD Portal has been developed saving the problems found in the first GIB Cloud prototype. More than 500 users are using this tool to collaboratively access to several health research and learning resources. At present, $80 \%$ of around 10.000 visits are from Africa. 


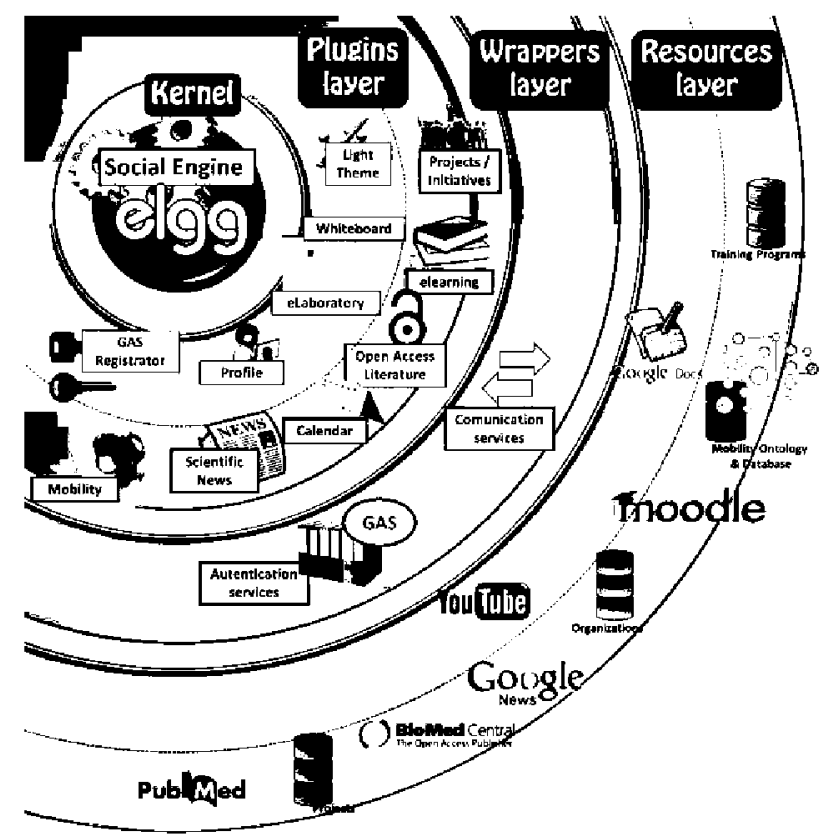

FIGURE 2. AFRICA BUILD Portal architecture

\section{ACKNOWLEDGMENTS}

This work has been partially funded by the European Commission through the AFRICA BUILD Coordination Action under the 7th Framework Programme (Grant Agreement no. 266474).

\section{REFERENCES}

1. Medpedia. URL:http://www.medpedia.com/. Accessed: 2013-03-01.

2. Eysenbach G. Medicine 2.0: social networking, collaboration, participation, apomediation, and openness. J Med Internet Res. 2008 Aug 25; 10(3): 22

3. Goble C, Stevens R. State of the nation in data integration for bioinformatics. J Biomed Inform 2008; 41:687-93.

4. Nordqvist C, Hanberger L, Timpka T, Nordfeldt S. Health professionals' attitudes towards using a Web 2.0 portal for child and adolescent diabetes care: qualitative study. J Med Internet Res. 2009 Apr 6; 11(2):e12.

5. Miller, M. Cloud computing. Web-based applications that change the way you work and collaborate online. Indiana, USA: QUE Indianapolis. 2008; ISBN: 0789738031

6. NIST definition of Cloud Computing (v. 15) 2010. URL:http://www.nist.gov/itl/cloud.cfm. 2013-03-01.

7. Dudley JT, Butte AJ. In silico research in the era of cloud computing. Nat Biotechnol 2010; 28:1181-5.

8. Schatz MC, Langmead B, Salzberg SL. Cloud computing and the DNA data race. Nat Biotechnol. 2010 Jul; 28(7):691-3.

9. Philbin J, Prior F, Nagy P. Will the next generation of PACS be sitting on a cloud? J Digit Imaging. 2011 Apr, 24(2):179-83. PubMed PMID: 20734101.

10. Schweitzer EJ. Reconciliation of the cloud computing model with US federal electronic health record regulations. J Am Med Inform Assoc. $2011 \mathrm{Jul} 4$.

11. Langer SG. Challenges for data storage in medical imaging research. J Digit Imaging. 2011 Apr; 24(2):203-7.

12. GIB Cloud. The Cloud for biomedical researchers. URL:http://sanger.dia.fi.upm.es/biomedcloudafrica/. Accessed: 2013-0301.

12. AFRICA BUILD | Building sustainable capacity for research for health in Africa. URL: http://africabuild.eu. Accessed: 201303-01.

13. AFRICA BUILD Portal. http://portal.africabuild.eu. Accessed: 2013-03-01. 